\title{
Optimalisasi Fungsi Dinas Perhubungan Kabupaten Tangerang Dalam Proses Rekomendasi Pembangunan Heliport
}

\author{
Togi Adnan Maruli Sinaga ${ }^{1}$, Rudy $^{2}$, Elfi Amir $^{3}$, Endang Sugih Arti ${ }^{4}$, Rini Sadiatmi ${ }^{5}$ \\ Program Studi Diploma III Penerangan Aeronautika \\ Politeknik Penerbangan Indonesia Curug \\ e-mail: prodi.pa@ppicurug.ac.id
}

\begin{abstract}
Abstrak
Fenomena berkembanganya pembangunan heliport di Tangerang Raya merupakan peluang bagi pemerintah daerah, dan menjadi bagian dari salah satu fungsi Dinas Perhubungan yang perlu dioptimalisasikan, melalui kegiatan Pengabdian Kepada Masyarakat kali ini Program Studi Diploma III Penerangan Aeronatika Politeknik Penerbangan Indonesia curug melakukan sharing session terkait pentingnya memahami teknis dan administratif terkait rekomendasi pembangunan heliport. Tujuan kegiatan ini adalah sharing session dengan para pejabat dan personel Dinas Perhubungan Kabupaten Tangerang terkait proses pembangunan heliport anatara kewenangan pemerintah daerah dan pihak regulator yang bertanggungjawab pada aspek teknis keselamatan penerbangan. Metode kegiatan adalah sosialisasi dan sharing kebijakan bersama tentang pembangunan heliport. Direktur Jenderal Perhubungan Udara merupakan mitra teknis berkaitan dengan aspek keselamatan penerbangan yang perlu dikolaborasikan dengan kewenangan pemerintah daerah berkaitan dengan wilayah dan Izin Mendirikan Bangunan (IMB). Kejelasan tentang proses rekomendasi pembangunan heliport di suatu daerah akan mendorong investor atau pemrakarsa pembangunan yang tentu saja diharapkan akan meberikan dampak langsung atau tidak langsung terhadap pembagunan dan kesejahteraan masyarakat setempat.
\end{abstract}

Kata Kunci : Pemerintah Daerah, Rekomendasi Pembangunan Heliport

\begin{abstract}
The phenomenon of the development of heliport construction in Greater Tangerang is an opportunity for the local government and is part of one of the functions of the Department of Transportation that needs to be optimized, through Community Service activities this time the Diploma III Study Program of Aeronautical Information at the Indonesian Aviation Polytechnic Curug held a sharing session regarding the importance of understanding technical matters. and administrative related to heliport construction recommendations. The purpose of this activity is a sharing session with officials and personnel of the Tangerang Regency Transportation Service regarding the heliport development process between the local government authorities and the regulators who are responsible for the technical aspects of flight safety. The method of activity is socialization and sharing of joint policies regarding heliport development. The Director-General of Civil Aviation is a technical partner related to aviation safety aspects that need to have collaborated with local government authorities related to areas and Building Construction Permits (IMB). Clarity about the recommendation process for heliport development in an area will encourage investors or development initiators which of course are expected to have a direct or indirect impact on the development and welfare of the local community.
\end{abstract}

Keywords: Local Government, Heliport Development Recommendations

\section{Pendahuluan}

Fenomena pertumbuhan heliport di Tangerang Raya menunjukan semakin banyak pendirian fasilitas tersebut. Hal ini mengindikasikan kebutuhan akan heliport semakin dibutuhkan 
masyarakat. Bisnis Taksi helikopter dan berbagai bisnis sejenis semakin ramai, termasuk uji coba drone berpenumpang juga makin menguatkan bahwa penerbangan jarak pendek seperti itu akan menjadi trend tidak lama lagi dimasa depan. Perkembangan ini merupakan peluang sekaligus tantangan bagi pemerintah daerah. Peluang artinya pemerintah daerah akan semakin banyak melayani permohonan izin mendirikan bangunan khususnya heliport atau istilah yang lebih popular helipad. Tantangan artinya pemerintah daerah diharapkan oleh masyarakat untuk mendapat pelayanan yang profesioanl dan lugas serta efisien berkaitan dengan inisiasi pembangunan heliport atau helipad tersebut. Zulaichah (2014); Suryawan \& Fatchoelqorib (2018) proses perizinan pengembangan industri penerbangan melibatkan stakeholder dan masyarakat sehingga dibutuhkan sosialisasi dan sinkronisasi kebijakan.

Lebih jauh Menteri PUPR sejak sekitar tahun 2015 telah mencanangkan akan membuat regulasi yang mewajibkan gedung-gedung dengan tinggi tertentu untuk dilengkapi dengan elevated heliport selain tangga darurat untuk kepentingan kondisi emergency. Peraturan Pemerintah Nomor 16 Tahun 2021 tentang Peraturan Pelaksanaan UU No.28 Tahun 2002 tentang Bangunan Gedung anatara lain mengatur tentang aspek kemudahan aksesibilitas dan akses evakuasi Dalam PP tersebut tidak ada ketentuan yang secara tegas mewajibkan adanya heliport/helipad mungkin nanti ditataran peraturan menteri hal terkait dengan kewajiban melengkapi helipad untuk gedung-gedung tertentu. Hal ini merupakan peluang selanjutnya bagi pemerintah daerah jika regulasi dimaksud telah diterapkan.

Memperhatikan Peraturan Bupati Kabupaten Tangerang dan Peraturan Walikota Tangerang Selatan, salah satu fungsi Dinas Perhubungan setempat adalah berkaitan dengan pelaksanaan pemberian rekomendasi ijin, mendirikan bangunan tempat pendaratan dan lepas landas helicopter. Bersama dengan Direktorat Jenderal Perhubungan Udara langkah-langkah pembangunan dan pengoperasian heliport dilaksanakan setelah mendapat izin mendirikan bangunan dari Pemerintah Daerah Kabupaten/Kota. Izin mendirikan bangunan heliport diberikan setelah mendapat rekomendasi dari Direktorat Bandar Udara Direktorat Jenderal Perhubungan Udara.

Pada tahun 2012 sejak dibentuknya Otoritas Bandar Udara yang menjadi kepanjangan tangan Direktur Jenderal Perhubungan Udara di daerah, prosedur permohonan rekomendasi pembangunan heliport didelegasikan kepada Kepala Otoritas Bandar Udara, sehingga alur prosedur tersebut sebagaimana gambar berikut ini : (SE.35/XII/2011)

Darmabakti: Jurnal Inovasi Pengabdian dalam Penerbangan

Volume 2, Nomor 1, Desember 2021 


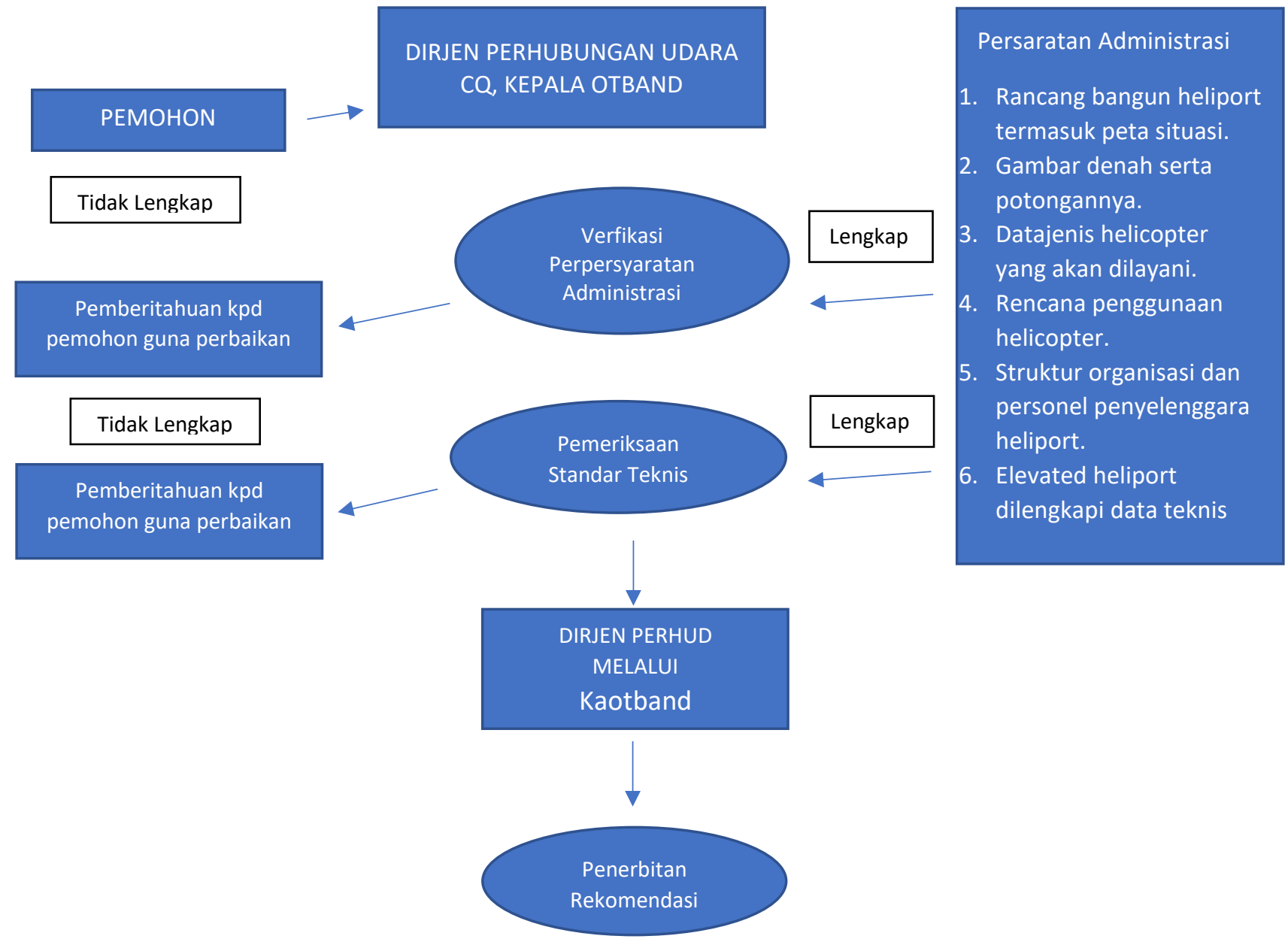

Gambar 1. Alur Prosedur Permohonan Rekomendasi

Kolaborasi antara institusi penerbangan dengan pemerintah daerah dibutuhkan sebagai bagian dari pengembangan industri penerbangan nasional yang mengutamakan standar keamanan (Susanto \& Sutrisno, 2018). Pemerintah daerah dapat mengambil peran dalam memberikan edukasi kepada masyarakat tentang penyelenggaraan bandar udara. Seperti hasil kegiatan Purba (2017) untuk mewujudkan industri penerbangan dengan membangun kesadaran hukum bagi stakeholders. Pelibatan pemerintah daerah sejak dini dalam pengembangan industri penerbangan dapat mengoptimalkan pembangunan berbagai sarana penerbangan di suatu daerah.

Tujuan pengabdian kepada masyarakat ini adalah sharing session dengan para pejabat dan personel Dinas Perhubungan Kabupaten Tangerang terkait proses pembangunan heliport anatara kewenangan pemerintah daerah dan pihak regulator yang bertanggungjawab pada aspek teknis keselamatan penerbangan.

\section{Metode}

Metode yang digunakan pada kegiatan pengabdian masyarakat ini adalah dengan presentasi yang disampaikan oleh 4 (empat) tim pihak Politeknik Penerbngan Indonesia dari Prodi Penerbang, Prodi Operasi Bandar Udara, Prodi Penerangan Aeronautika dan Prodi Teknik Navigasi Udara. Selanjutnya dari masing-masing presentasi diadakan forum tanya jawab terkait substansi yang dipresentasikan. Karena audience kegiatan ini adalah para pejabat Dinas Perhubungan Kabupaten

Darmabakti: Jurnal Inovasi Pengabdian dalam Penerbangan

Volume 2, Nomor 1, Desember 2021 
Tangerang, maka tanya-jawab yang dilaskukan lebih bersifat sharing session atau juga bersifat konsultasi dari masing-masing pihak.

Beberapa masukan dari pihak audience antara lain agar kegiatan pengabdian kepada masyarakat ini dibuat berseri menyangkut masalah-masalah penerbangan terkini yang ada hubungannya dengan keberadaan pemerrintah daerah. Hal tersebut karean sejak adanya kebijakan untuk dikembalikannya ke pusat beberapa kewenangan pemerintah daerah terutama berkaitan dangan masalah teknis transportasi laut dan transportasi udara, mereka hanya mendapat sosialisasi dan pengetahun terkait masalah trasnportsi darat, sementara masih ditemukan tugas fungsi yang sedikit banyaknya berkaitan dengan trasnportasi udara, khususnya berkaitan dengan pembangunan heliport di daerah setempat.

Kami dari Prodi Penerangan Aeronautika mengusulkan kepada pihak Pusat Penelitain dan Pengabdian Kepada Masyarakat (PPM) PPI-Curug agar membuat semacam road-map yang memungkinkan dilaksanakan kegiatan pengabdian yang berkesinnambungan dan mempunyai manfaat kongkrit kepada subyek dan obyek kegiatan pengadian masyarakat dimaksud.

\section{Hasil dan Pembahasan}

Kegiatan pengabdian kepada masyarakat ini dihadiri oleh Kepala Dinas Perhubungan Kabupaten Tangerang dan 40 personil Dinas Perhubungan Kabupaten Tangerang serta perwakilan konsultan konstruksi setempat, Kegiatan membahas 4 hal sebagai berikut : Prodi Penerbangan menyampaikan Sosialisasi tentang Training Area PPI-Curug, Prodi Operasi Bandar Udara menyampaikan Sosialisasi kegiatan yang dapat membahayakan operasi penerbangan pada KKOP di wilayah Kabupaten Tangerang, Prodi Teknik Navigasi Udara menyampaikan Sitting Cretaria peralatan telekomunikasi navigasi dan pengamatan penerbangan, dan Prodi Penerangan Aeronautika menyampaikan. Sosialisasi terkait rekomendasi pembangunan heliport di Tangerang Raya kepada personil Dinas Perhubungan Kabupaten Tangerang. Sosialisasi yang dilakukan bersama pihak pengembang dengan pemerintah daerah dilakukan untuk membangun kesamaan persepsi tentang pembangunan yang ada di setiap daerah (Herdiana, 2018).

Pembahasan dari Prodi Penerangan Aeronautika dengan judul Optimalisasi Fungsi Dinas Perhubungan Kabupaten Tangerang diawali dengan membahas Peraturan Bupati Kabupaten Tangerang Nomor 93 Tahun 2016 khususnya tentang salah satu fungsi Dinas Perhubungan pasal 23 ayat 4 poin d pada Seksi Teknik Prasarana berkaitan dengan helipad juga dibahas tentang Peraturan Walikota Tangerang Selatan Nomor 58 Tahun 2016 tugas pokok dan fungsi Dinas Perhubungan Kota Tangerang Selatan yaitu "Membantu Walikota dalam merencanakan, melaksanakan, mengawasi dan mengendalikan kegiatan dibidang perhubungan sesuai dengan kebijakan pemerintah daerah", Salah satu fungsi menurut peraturan walikota tersebut adalah "Pelaksanaan pemberian rekomendasi ijin, saran teknis mendirikan bangunan tempat pendaratan dan lepas landas helikopter"

Dari dua peraturan bupati dan peraturan walikota tersebut dibahas bagaimana peluang rekomendasi pembangunan heliport dari sisi pemerintah daerah yang meliputi hal-hal terkait dengan kewenangan PEMDA, masalah teknis terkait dengan pembangunan surface maupun elevated heliport juga disampaikan, peluang pendapatan PEMDA melalui pendapatan retribusi dan pendapatan lain yang sah.

Dari segi regulasi teknis dibahas berbagai regulasi tingkat menteri perhubungan dan Direktur Jenderal Perhubungan Udara yaitu KP.215 Tahun 2019 tentang MOS CASR 139 Volume II Tempat Pendaratan dan Lepas Landas Helikopter dan rujukan regulasi terbaru Peraturan Menteri Perhubungan No.32 Tahun 2021 tentang Standar Pembangunan Bandar Udara serta Tempat Pendaratan dan Lepas Landas Helikopter.Aspek internasional terkait dengan heliport diperkenalkan

Darmabakti: Jurnal Inovasi Pengabdian dalam Penerbangan

Volume 2, Nomor 1, Desember 2021 
tentang salah satu dokumen International Civil Aviation Organization (ICAO) yaitu ICAO Anneex 14 Aerodrome, Volume II Heliport, edisi kelima tahun 2020.

Salah satu regulasi yang dibahas terkait dengan penerbangan khususnya helikopter dan heliport adahan Peraturan Pemerintah sebagai salah satu tindaklanjut Undang-Undang Nomor 11 Tahun 2020 tentang Cipta Kerja yaitu PP Nomor 32 Tahun 2021 Bidang Penerbangan. Dalam Peraturan Pemerintah tersebut banyak dibahas peran pemerintah daerah terkait dengan penerbangan.

Dalam PP Nomor 32 Tahun 2021, tanggal 2 Februari 2021 tersebut disebutkan bahwa "Pengoperasian temapt pendaratan dan lepas landas helikopter dilaksanakan sesuai standar Menteri Perhubungan dan wajib memenuhi ketentuan keselamatan dan keamanan penerbangan. Disebutkan bahwa pemrakarsa pembangunan heliport meliputi Pemerintah Pusat, Pemerintah Daerah, Badan Usaha Milik Negara, Badan Usaha Milik Daerah atau Badan Hukum Indoesia. Disebutkan pula bahwa "Standar pembangunan sebagaimana dimaskud bertuan untuk memastikan perencanaan sesuai dengan pelaksanaan pembangunan heliport dalam menjamin keselamatan,keamanan dan kenayamanan penerbangan serta pelestarian lingkungan hidup.

Pada kegiatan ini disampaikan pula mekanisme pengajuan usul perizinan terkait pembangunan dan pengoperasian heliport dan contoh dari salah satu kabupaten/kota di Indonesia yang telah memiliki standar pelayanan ijin mendirikan heliport sesuai dengan kewenangan yang dimiliki pemerintah daerah.

\section{Kesimpulan}

Kegiatan pengabdian kepada masyakat ini telah berjalan secara interaktif dan dinamis selama kurang lebih 6 jam dan menurut peserta yang hadir cukup bermanfaat dari aspek pengetahuan penerbangan yang berhubungan dengan tugas pokok dan fungsi instansi Dinas Perhubungan Kabupaten Tangerang, dengan harapan agar kegiatan seperti ini dapat dilakukan secara berkesinambungan dan guna dapat menambah wawasan matra udara bagi pejabat dan personel instansi tersebut.

\section{Penghargaan/Ucapan terima kasih}

Terima kasih dan penghargaan kami sampaikan kepada Pemerintah Daerah Kabupaten Tangerang melalui Kepala Dinas Perhubungan yang telah memungkinkan terlaksananya kegiatan Pengabdian Kepada Masyarakat PPI-Curug Tahun 2021 dengan baik.

Terima kasih kepada Direktur PPI-Curug melalui Kepala Pusat Penelitian dan Pengabdian Kepada Masyarakat (PPM) yang telah memberi kesempatan untuk melaksanakan kegiatan Tri Dharma ini kepada kami Tim Prodi Penerangan Aeronautika PPI-Curug.

\section{Daftar Pustaka}

Herdiana, S. (2018). Sosialisasi Kebijakan Publik: Pengertian dan Konsep Dasar. Jurnal Ilmiah Wawasan Insan Akademik, 1 (3), 13-28.

ICAO (2020) Annex 14 Aerodrome-Volume II Heliport, $5^{\text {th }}$ edition,999 Robert-Bourassa Boulevard,Montreal,Quebec,Canada H3C 5H7.

Peraturan Pemerintah Repulik Indonesia (2021) Nomor 32 Tahun 2021 Tentang Tindaklanjut Undang-Undang Cipta Kerja Bidang Penerbangan.

Peraturan Pemerintah Republik Indonesia (2021) Nomor 16 Tahun 2021 tentang Peraturan Pelaksanaan Undang-Undang Nomor.28 Tahun 2002 tentang Bangunan Gedung 
Peraturan Menteri Perhubungan (2021) Nomor 32 Tahun 2021 Tentang Standar Pembangunan Bndar Udara serta Tempat Pendaratan dan Lepaslandas Helikopter.

Peraturan Direktur Jenderal Perhubungan Udara (2019) Nomor KP.215 Tahun 2019 Tentang Manual of Standard (MOS) 139 Volume II Tempat Pendaratan dan Lepaslandas Helikopter.

Peraturan Walikota Tangerang Selatan (2016) Nomor 58 Tahun 2016 Tentang Kedudukan,Susunan Organisasi,Tugas,Fungsi dan Tata Kerja Dinas Perhubungan.

Peraturan Bupati Tangerang (2016) Nomor 93 Tahun 2016 Tentang Kedudukan,Susunan Organisasi,Tugas,Fungsi dan Tata Kerja Dinas Perhubungan.

Purba, H. (2017). Mewujudkan Keselamatan Penerbangan dengan Membangun Kesadaran Hukum bagi Stakeholders melalui Penerapan Safety Culture. Jurnal Hukum Samudra Keadilan, 12 (1), 95-110.

Surat Edaran Direktur Jenderal Perhubungan Udara (2011) Nomor 35/XII/2011 Tentang Edaran Keselamatan Penerbangan Sipil Bgian 139-06,Pendelegasian Kewenangan Penerbitan Rekomendasi Teknis Pembangunan Heliport (Elevated Heliport/Surface Level Heliport) Kepada Kepala Kantor Otoritas Bandar Udara.

Surat Keputusan Direktur Jenderal Perhubungan Udara (2010) Nomor SKEP/41/VI.2010 Tentang Petunjuk dan Tata Cara PKPS Bagian 139-06,Prosedur Pembangunan dan Pengoperasian Tempat Pendaratan dan Lepas Landas Helikopter.

Surat Keputusan Direktur SKK-MIGAS (2015) SK Nomor 0141-SKKO.0000/2015/S0 Tentang Pedoman Tata Kerja Prosedur dan Sertifikasi Kegiatan Kebandaran dan Kemaritiman Revisi01 .

Suryawan, R., \& M. Fatchoelqorib. (2018). Penerbangan Perintis dalam Mengembangkan Perekonomian di Pulau Karimunjawa. Jurnal Manajemen Transportasi \& Logistik, 5 (2), 161168.

Susanto, A., \& Sutrisno, A. (2018). Analisa Standar Keamanan terhadap Keselamatan Penerbangan di Bandar Udara Komodo Labuan Bajo. Airman: Jurnal Teknik Dan Keselamatan Transportasi, 1(1), 1-4. https://doi.org/10.46509/ajtk.v1i1.51.

Undang-Undang Nomor 1 Tahun 2009 Tentang Penerbangan.

Zulaichah. (2014). Pengaruh Fasilitas Bandar Udara Terhadap Kinerja Ketepatan Waktu Maskapai Penerbangan. WARTA ARDHIA: Jurnal Perhubungan Udara, 40 (4), 223-234. 